\title{
Work and Stay: Explaining Perceived Discrimination Among Romanian Labor Migrants
}

\section{Sergiu Gherghina ${ }^{1}$}

Published online: 2 September 2020

(C) The Author(s) 2020

\begin{abstract}
Research dealing with perceptions of discrimination among migrants investigated its consequences on their daily lives. However, little systematic attention had been paid to the determinants of perceived discrimination among migrants. This article aims to explain the causes for which migrants see themselves discriminated against in their country of residence. The statistical analysis uses individual-level data from an original survey conducted in 2018 among Romanian migrants. The results indicate that poor relations with natives, a job below capabilities, and the temporary status of migration contribute to higher perceptions of discrimination.
\end{abstract}

Keywords Perceived discrimination $\cdot$ Relations $\cdot$ Job $\cdot$ Length of stay

\section{Introduction}

Discrimination is the unequal treatment of persons or groups in society. It ranges from verbal abuse or feeling less valued as a human being to unfair practices, bias, and harassment (Szczepura et al. 2004; Agudelo-Suárez et al. 2009). Ethnic discrimination conveys individuals the message that they are devalued or excluded from the larger society due to their ethnic group membership (Wong et al. 2003). This is an important caveat for migrants who are newcomers in a country and see themselves the targets of such practices and can influence their lives (Krieger et al. 2006; Hatch et al. 2016). In general, there are two types of discrimination: real or perceived. The former is difficult to capture and it is usually reflected through reports of discriminatory behavior or through statistics that examines differences across various ethnic groups in society. Recent evidence shows that real ethnic discrimination in hiring decisions remains quite widespread across the OECD countries since 1990 (Zschirnt and Ruedin 2016). The

Sergiu Gherghina

sergiulor@yahoo.com

1 Department of Politics, University of Glasgow, Glasgow, Scotland 
perception of discrimination is far more investigated and researchers use subjective accounts of those who consider themselves to be victims of discrimination.

Most research about the perceptions of discrimination among migrants investigate its consequences on their daily lives. One of the common consequences is psychological and impacts on migrants' integration and mental health (Finch et al. 2000; Sangalang et al. 2019). A study conducted in Norway finds that for Sami people living in minority areas, self-reported discrimination is associated with a broad range of negative health indicators (Hansen 2015). Other important consequences of perceived discrimination are high levels of depression and stress among migrants (Brody et al. 2006; Aichberger et al. 2015; Keys et al. 2015). With some notable exceptions (Phinney et al. 1998; Shorey et al. 2002; MottiStefanidi and Asendorpf 2012), little systematic attention had been paid to the determinants of perceived discrimination among migrants. To fill this gap in the literature, this article aims to explain the causes for which migrants see themselves discriminated against. The research question that guides this paper is: What determines the perceptions of discrimination among Romanian migrants? It addresses the issue of perceived discrimination against the self and does not account for perceived discrimination against the ethnic group. The analysis refers exclusively to individual discrimination — as opposed to institutional discrimination — and focuses on the Romanian migrants for two reasons: they are one of the largest group of migrants in Europe and there are documented cases of ethnic discrimination against them.

To answer this question, the paper will seek to identify the effect of several individual-level variables on the perceptions of discrimination. These variables reflect the experiences and attitudes of migrants towards their countries of residence and of origin. The paper argues and tests for the explanatory potential of occupying jobs below capabilities, planned stay in the host country, sense of belonging to migrants' own ethnic group, positive relations with the natives, and number of interactions with members of other groups of migrants. In addition to these main effects - for which hypotheses are formulated - the paper will also control for a few variables identified in the literature as having an impact: length of residency, knowledge of language, education, age, and gender. The analysis uses individual-level data from an original web survey conducted in January 2018 among Romanian migrants, which includes 1839 complete responses. The paper uses statistical analysis (bivariate correlations and ordinal logistic regression) to explain the variation in the perception of discrimination.

The remainder of this paper proceeds as follows. The first section reviews the literature about the causes of perceived discrimination and formulates several testable hypotheses. The second section includes the research design with emphasis on the case selection, variable operationalization, data, and methods used for analysis. Next, I provide a brief overview of the waves of Romanian migration to contextualize the findings of this study. The fourth section includes the statistical analysis and interprets its results with focus on the main effects. The conclusions summarize the key findings of the paper, discuss the broader implications for the study of perception of discrimination among migrants, and develop directions for further research.

\section{Literature Review and Hypotheses}

The perception of discrimination depends on individuals' interpretations of the behavior of others. Negative events are often attributed to discrimination in the sense that 
whenever poor or unequal treatment is applied to individuals, they will perceive it as discriminatory behavior (Ruggiero and Taylor 1995). There are several potential causes for such a perception, rooted in several theories. Since this article aims to identify and analyze the determinants of individual perceived discrimination in general (as opposed to particular settings such as the workplace characteristics), these theoretical approaches are combined to formulate several testable hypotheses. The article focuses on individual-level characteristics because these reflect directly the experiences and attitudes of migrants and indirectly the actions of political institutions/authorities or of employers.

\section{Work Below Capabilities and Planned Stay}

On the labor market, a great deal of migrants generally fills jobs where there are shortages of workers. This usually happens when native workers refuse to do low-skill jobs. Although the skills required for the job are sometimes below their capabilities, migrants are willing to accept the job because the wages in that country are considerably higher than in their home country. In the most recent decades, this has been the case with West European countries who offer many low-skill jobs and migrants from East European countries. For example, skilled migrant workers in the UK claimed that performing low-skill work there was a much better option compared with the very low wages in post-communist countries (MacKenzie and Forde 2009). Earlier findings illustrate that workplaces with high numbers of migrants from the post-communist countries who joined the EU in the last wave are characterized by numerical flexibility, job insecurity, dependence on employment agencies, and low pay (McDowell et al. 2008). A study on Polish and Lithuanian worker migrants reveals that they perform jobs which do not match their academic and vocational qualifications (Anderson et al. 2008). The Romanian migrants are no exception to this general picture since many of them left the country to seek for better paid jobs (Anghel 2013; Trandafoiu 2013). They accept jobs that bring financial advantages although they are sometimes well below their capabilities and other times outside their realm of expertise. In brief, for higher salaries than in their countries of origin, East European migrants choose downward occupational mobility in which they have to endure long working hours and precarious work (Ciupijus 2011).

Migrants who have less attractive jobs, accept jobs below their qualifications and work under unfavorable conditions are more vulnerable to individual discrimination. Interviews conducted with migrant workers in England and Wales showed that many respondents believed that they were often allocated to the worst shifts, were denied the benefits and conditions available to local workers, and were subject of harassment by supervisors and co-workers (McKay et al. 2006). Migrants with high qualifications either worked in the home country on a position for which they were qualified or were trained for a superior job compared with what they perform in the country of residence. The downward occupational mobility makes this category of migrants sensitive to the physical conditions of their new jobs and to the psychological climate of workplaces. Under these circumstances, migrants who perform jobs under their capabilities are more likely either to notice inappropriate behavior from employers and colleagues or to interpret some behavior as inappropriate due to their higher standards. Both processes increase the likelihood of perceived discrimination. 
There is a limited number of migrants who decide straight away in favor of permanent relocation in a particular country. The migration experience is often temporary and sometimes not even a one-shot process, with several attempts made before settling in. In this sense, migration is not a unidirectional phenomenon and many migrants return to their home places (Dustmann et al. 1996; Constant and Massey 2002; Dustmann et al. 2011). Return migration is a natural process that can have several causes. Among these, the economic reasoning is quite prominent. Migration can be a reaction to where human capital can be acquired more efficiently, where the return to human capital is highest and where the financial gains allow for more purchasing power (Dustmann and Weiss 2007; Dustmann et al. 2011). In some instances, migrants have to decide between maximizing lifetime earnings and the return meant to overcome market deficiencies at home (Constant and Massey 2002). At the same time, migrants can be rational financial maximizers who decide to live in various places after assessing costs and benefits. They could decide to return when their financial gains in the host countries are in decline (Yang 2006) or when the financial needs for which they migrated in the first place are covered (Stark 1996).

Migrants who plan for a short stay are usually oriented towards earning money than aiming for integration in the society of residence. The desire to accumulate financial resources determines them to accept a variety of jobs and to be exposed more to discriminatory practices and attitudes. On the contrary, migrants who plan their stay for long-term in a country of residence are more oriented towards integration and more selective with respect to their jobs. Their primary aim is to find the appropriate means that will allow them to survive and prosper on the long run in the host society. Many migrants from this category choose carefully their workplace and have a higher tendency - compared with the temporary migrants - to elicit positive responses from their environment. Some of them also bring their families along and usually that happens after positive experiences in the country of residence. Following these theoretical arguments, I expect that the perception of discrimination in the country of residence will be higher among those migrants who:

H1. Occupy jobs below capabilities

H2. Have planned a temporary short stay in the country of residence.

\section{The Attributional Perspective}

This theory argues that the personality characteristics of individuals drive them into assessing a situation as being discriminatory. This rests on the idea that beliefs and dispositions shape the understanding of every situation and determine the attributions that individuals make for different events (Phinney et al. 1998). Previous studies analyzed a series of personality characteristics and found mixed evidence. For example, lower individual self-esteem and less personal and interpersonal control lead to higher perceived personal discrimination (Shorey et al. 2002). Similarly, another piece of research found that individuals with a greater sense of control and higher self-esteem perceived less discrimination in a given event (Ruggiero and Taylor 1995). However, the same authors found no effect of self-esteem on perceived discrimination in two later studies devoted to women, Asians, and Blacks (Ruggiero and Taylor 1997). Another 
piece of research had contradictory findings according to genders: low self-esteem leads to higher perceptions of discrimination among men, but for women there is no relationship between the two variables (Kobrynowicz and Branscombe 1997). This variable yields inconsistent explanatory potential across various contexts and makes little sense to include it in the analysis. Nevertheless, it lies at the core of esteem attitudes towards the ethnic group, to be detailed in the following paragraph, that could make a difference with respect to perceived discrimination.

Particular to the study of discrimination, some attributes are rooted in the way individuals position themselves towards groups. The social identity theory summarizes the core elements of such a positioning. According to this theory, individuals need to positively assess their own group (called in-group) as being superior to other groups (called the out-groups). To achieve this result, individuals compare and selectively perceive the positively valued characteristics of their in-group and the negatively valued characteristics of the out-groups (Turner 1981; Tajfel 1982). Following this line of argument, the ability of migrants to have a strong identity within their own ethnic group may increase their self-esteem and thus lower the likelihood of perceived discrimination (Phinney et al. 1997). This is different from the individual self-esteem described above and rests on different principles. High self-esteem of migrants for their ethnic group is likely to serve as a buffer against perceived discrimination (Phinney et al. 1998).

More discrimination is perceived in contexts that involve prototypic perpetrators and prototypic victims (Phinney et al. 1998). For example, in the USA where the African Americans had been for a long period the victim of discrimination from the white population, the African American individuals are more likely to report the existence of discrimination in contemporary events compared with white individuals (Inman and Baron 1996). This perception is based on the traditional relations between the two ethnic groups and on the usual status of each group. In general, underprivileged groups are more likely to perceive discrimination. Consequently, positive identification with one's ethnic group may lead to lower perceptions of discrimination.

At the same time, the ability to get along with members of other ethnic groups (e.g., those from the host country), rather than sticking to their own group, may diminish the perception of discrimination (Phinney et al. 1998). The positive interaction with locals, for example, could increase migrants' feelings of competence and (re)assure them about the progress on the path to integration in the host society. Greater feelings of competence and security regarding own actions are conducive to lower likelihood of perceived discrimination. The underpinning logical mechanism is that such individuals, due to the positive feelings they develop, are (a) less likely to attribute ambiguous social situations to discrimination against them and (b) more likely to be rewarded with non-discriminatory actions by the environment due to the positive ties they cultivate (Shorey et al. 2002; Motti-Stefanidi and Asendorpf 2012).

In addition to the quality of interactions, the quantity can also make a difference. For example, the regular interaction with members of other migrant groups could provide access to different experiences and interpretations of events and thus result in greater awareness and understanding of complex issues. The interactions are likely to nuance the broader picture and to take the migrants away from their own filters (which may be culturally biased) through which they understand what happens. The absence of interactions with other groups can fuel feelings of victimization, which lead to 
perception of discrimination, as indicated in a study of young migrants in Finland (Strohmeier et al. 2011). The isolation from other groups can lead to feelings of anxiety and victimization, which are conducive to the perception of discrimination. All these theoretical arguments make us believe that perceptions of discrimination will be higher among those migrants who:

H3. Have lower esteem for the ethnic group to which they belong

H4. Have poor relations with the natives

H5. Have limited interactions with members of other groups of migrants.

\section{Controls}

In addition to these main effects, this article controls for five variables that were identified in the literature as potential drivers of perceived discrimination. The first control variable is the migrants' length of residency. Earlier research shows that migrants report more discrimination with increasing time in the country of residence (Goto et al. 2002). This effect can be due to more exposure to and experience of situations and interactions in which discrimination occurs. An alternative explanation is that with time migrants become more aware of their minority status in the host society and could be better able to recognize discrimination (Gee et al. 2006).

The next four controls are derived from the sociocultural theory and these are the knowledge of language, the level of education, age, and gender. The sociocultural theory posits that the demographic characteristics of the individuals involved in the event are likely to shape their perception about discrimination. Earlier research identified several factors that characterize such groups and may be conducive to more perceived discrimination: the ability to speak the language of the host community, the degree of integration, the level of education, the income, age, and gender (Floyd and Gramann 1995; Vega et al. 1995; Inman and Baron 1996). At the workplace, research conducted in the USA warns about the possible link between belonging to a vulnerable ethnic group with a low socioeconomic level and a higher perception of discrimination experienced (Krieger et al. 2006). ${ }^{1}$

\section{Research design}

To test these effects, the analysis uses original data from a survey conducted in January 2018 among first-generation migrants from Romania. The dataset includes 1839 respondents who were selected based on a maximum variation sampling. There is no official statistics about the number of Romanian migrants (only estimates, see below) and their profile. The characteristics of the entire population of Romanian migrants are unknown and, as such, a probability representative sample cannot be drawn. Non-

\footnotetext{
${ }^{1}$ I controlled for a series of other variables such as language proficiency (in country of residence) at the time of survey, medium of residence, multiple migration, and occupation. None of these has a strong or statistically significant on the perceived discrimination and they were excluded from the analysis to keep the statistical models parsimonious.
} 
probability sampling is often used to study populations where formal access to complete lists of members is not possible. Migrants are often one of these categories due to several reasons, e.g., the migration within the EU requires no formal cross-border controls or procedures of registration to authorities and irregular migration. The maximum variation sampling is a purposive sampling technique used to increase the variation on several key variables for research (Patton 2005; Emmel 2013). One important disadvantage of purposive samples is the difficulty to generalize its findings to a broader population since they are not representative (Emmel 2013; Schreier 2018).

The maximum variation sampling used for this survey aimed to maximize the variation in terms of migrants' country of residence, experience with migration, age, education, gender, and occupation. Some of these variables are not used in this paper and their variation is not reported. Appendix Table 3 is illustrative for the variation on the variables included in the analysis. To provide an illustration of this variation, the age of respondents is distributed as follows: 18-30 years (21\%), 31-40 years $(34 \%)$, $41-50$ years $(31 \%)$, and over 50 years $(14 \%)$. This sampling strategy confines the findings presented in this article to our respondents. However, due to the different profile of the migrants included in the analysis, they are informative and with important implications for the study of perceived discrimination.

The respondents were neither pre-selected nor part of a pool of available individuals. The survey was conducted online and was distributed through messages on Facebook groups or discussion forums of Romanians living abroad, and by e-mails sent to representatives of Romanian associations and organizations. The use of social media to collect data has several advantages such as the examination of people's attitudes and behaviors in a setting that is part of their everyday lives or the possibility to reach groups that are often under-represented in traditional research (Moreno et al. 2013). The disadvantages of online data collection refer mainly to the access of respondents to devices and Internet, survey fraud, and the absence of an interviewer to explain unclear issues (Sue and Ritter 2012). The latter can lead to lower response rates in online surveys compared with traditional surveys (Pedersen and Nielsen 2016). To compensate for the absence of an interviewer, there was a pilot study of one week prior to the fielding of the survey. The pilot included two procedures. First, the survey was sent to 40 respondents from a previous survey to check response rates and if specific questions triggered their decision to quit the survey. Second, I used random cognitive testing to see whether questions made sense to respondents who were contacted via e-mail. The pilot survey revealed no particular problems. To increase the number of responses, several reminders were sent. The article reports only the total number of complete answers received to the questionnaire.

The Romanian migrants were selected as subject of this study for two reasons. First, Romania has one of the largest migrant populations in Europe, both in terms of estimated raw numbers of migrants and as a percentage of estimated migrants relative to the total population in the home country (Dospinescu and Russo 2018; International Organization for Migration 2020); see the "Waves of Romanian Migration" section. Several studies indicate that the preferred destinations of migration for Romanians are Italy, Spain, UK, Germany, France, and the USA (Anghel 2013; Trandafoiu 2013). This is reflected also in the sample of respondents for the survey where almost $70 \%$ of those who filled in the online survey live in one of these six countries. The remaining $30 \%$ live in other 38 countries around the world as far as Australia, Japan, New 
Zealand, Singapore, or Tonga. A large majority of migrants included in the sample live in European countries. Second, previous studies indicate the existence of discrimination against Romanian migrants in various countries (Agudelo-Suárez et al. 2009; Fox et al. 2015; Marcu 2015). These instances make the Romanian migrants likely to feel discriminated against compared with, for example, other groups of migrants that did not face such a behavior from host societies.

\section{Variable Operationalization}

The dependent variable of this study is measured on a five-point ordinal scale as the answer to the following question: "During your stay in this country, did you feel discriminated against?". The possible answers range between "not at all" (1) and "very much" (5). The variable job below capabilities (H1) is operationalized through the following question "Can you tell us which of the following issues has characterized your stay in the current country of residence?". The available answers consist of a list of issues from which respondents can choose. One of these options is "performed a job below your capabilities and level of training". The answers are coded dichotomously with value 1 when respondents indicate that they occupied such a job and value 0 when they do not select this option.

The planned duration of stay $(\mathrm{H} 2)$ is measured through the answers provided to the question "When you reached this country of residence, for how long have you planned your stay?". Available answers range on a five-point ordinal scale from "temporary short stay (less than one year)" to "permanent". The sense of belonging to the group (H3) is measured through a proxy asking respondents about their emotional attachment to the home country: "How much do you feel emotionally attached to Romania?". Available answers ranged from "not at all" (coded 1) to "very much" (coded 5). The relationships with natives ( $\mathrm{H} 4)$ are measured on a five-point ordinal scale based on the following question: "How would you describe your relationships with those from the locality in which you live at the moment (we refer in particular to those born in the host country)?". The possible answers range between "very poor" (coded 1) and "very good" (coded 5). The frequency of interactions with members of other migrant groups is the answer to the question "How often do you currently spend your free time (including on Internet) in the country of residence with people who came from other countries?". The available answer options range from "not at all" (coded 1) to "very often" (coded 5).

The first control variable, the length of residency, is measured through the answers to the following question "For how long do you live in this country (please mention the total period, not the one of interrupted stay)?". The possible answers were "less than six months" (coded 1), "6 months to one year" (2), "one to three years" (3), "three to six years" (4), and "more than six years" (5). The difficulty to speak the language is measured similarly to $\mathrm{H} 1$ : it is one of the issues that respondents can identify as an issue that characterized their stay in the current country of residence; it is also coded dichotomously with 0 for the absence and 1 for the presence of language difficulties. Education is recorded as the highest degree completed, coded on an ordinal scale that ranges between "primary school" (1) and "post-graduate studies" (7). Age is measured through the year of birth, while gender is a dichotomous variable ( 1 for women and 2 for men). For all the 
variables, the "DK / NA" answers are treated as missing values and excluded from the analysis.

The empirical analysis from the following section starts with a general discussion about the Romanian migration and distribution of perceived discrimination, based on the survey. It is followed by inferential statistics that includes bivariate and multivariate relationships. The latter takes the form of ordered logistic regression because the dependent variable is an ordinal measure. The statistical models are reported for the entire sample of respondents. I have also run models with country dummies to account for variation according to the country of residence. These models show no strong or statistically significant effect of the country dummies on the perception of discrimination; their results resemble the ones without country dummies. For reasons of parsimony and easiness of interpretation, this article presents the version without country dummies. Before running the regression, I tested for multicollinearity and the results indicate no highly correlated predictors, i.e., the highest value is around 0.35 and the VIF values are lower than 1.23 for every estimate.

\section{Waves of Romanian Migration}

Romania has the highest increase in migration among the EU member states in the last three decades (Dospinescu and Russo 2018). The migration of Romanians started after the breakdown of the communist regime in 1989 and includes several waves in which both low and high-skilled individuals left the country (Gherghina and Plopeanu 2020). Some Romanian migrants change destinations in a process called multiple migration (Ciobanu 2015). Earlier studies indicate that the main reasons behind the Romanian migration are related to possibilities for greater financial gains (for migrants and their families at home), better job opportunities, and education purposes (Sandu 2006; Stănculescu and Stoiciu 2012; Dospinescu and Russo 2018). After the regime change, Romanians had the possibility to go abroad for work or study. Travel abroadespecially to Western countries - was heavily controlled and restricted under the communist rule. The Romanian migration between 1990 and 2020 can be divided in three major waves. The first wave took place during the 1990 s and is characterized by temporary migration driven by Romania's economic instability and poor performance. The hardships of transition and the slow and problematic privatization led to unemployment and low living standards for many citizens. In this period, the migrants were usually men who worked abroad and provided financial assistance to their families in Romania (Sandu 2006). Among these, there were many temporary migrants who sought work in the Schengen area (Sandu et al. 2004).

A second wave of migration began in the early 2000 s, coinciding with the opening of the Romanian negotiations for EU accession. The latter was supposed to happen in 2004, together with most other post-communist countries, and visas were lifted a couple of years before that date. The visa-free regime marked an explosion in terms of Romanian migration: between 2000 and 2010 estimates indicate that the number of migrants tripled (Dospinescu and Russo 2018). In 2009 and 2010, approximately 26\% of the Romanian households had at least one family member that migrated (Stănculescu and Stoiciu 2012). A great deal of this second wave consisted of labor migrants, with Italy and Spain as preferred destinations (Suciu 2010). The main pulling factor for the 
Romanian migrants in these two countries was represented by the existing networks of co-national migrants (Elrick and Ciobanu 2009). This wave includes seasonal, temporary, and permanent migrants. Related to the latter, there is a large increase of highskilled migration in this time period: many Romanian professionals from different fields - especially from health services - go abroad (Dospinescu and Russo 2018).

The third wave started around the time of the financial crisis and is characterized by larger numbers of labor migrants (both high and low skilled) compared with the previous decade. The vast majority of Romanians who were abroad during the financial crisis did not return home when facing difficulties in the country of residence (Gherghina and Plopeanu 2020). Instead, they stayed and tried to identify solutions, or migrated to another country (Marcu 2015). After 2010, the number of highly educated migrants increased dramatically, with many students seeking to complete their education or find a job abroad (Dospinescu and Russo 2018). There are currently millions of Romanian labor migrants abroad. They are a large share of the electorate in their home country and they caught the attention of political actors in Romania. Their needs and grievances make the object of political debates especially that Romanian labor migrants are quite active in terms of political participation (Gherghina 2016; Vintila and Soare 2018).

After this brief overview regarding the phases of Romanian migration and general profile of migrants, it is useful to see how those who took the online survey perceived discrimination. The following section discussed at length the results of analysis and links them back to earlier findings and existing theories.

\section{Analysis and Results: Good Relations (with Natives) and Poor Jobs}

Figure 1 depicts the distribution of respondents $(N=1839)$ according to their perception of individual discrimination. The horizontal axis reflects the percentage of respondents. The distribution indicates that a relatively equal share of the Romanian migrants experienced no, little, or some discrimination. Each of these three options was selected by slightly more than one quarter of the respondents to our survey. This means that few Romanian migrants experience much or very much discrimination. The latter was the case for one in 10 respondents. These observations are consistent across the countries included in the analysis: there is no country that stands out in terms of perceived discrimination against respondents. Overall, the distribution indicates the existence of important differences between the perceptions of individual discrimination among the respondents to this survey.

\section{Bivariate Correlations}

Let us now turn to the bivariate relationships and observe to what extent the variables included in the hypotheses and the controls correlate with the individual perception of discrimination. Table 1 includes the values of the correlation coefficients, which are non-parametric due to the ordinal nature of most variables. The direction, size of the coefficients, and statistical significance at the 0.01 level provide empirical support for all but one hypothesized relationship. The results indicate that respondents who perform jobs below their capabilities, planned a short stay in the host country, have 


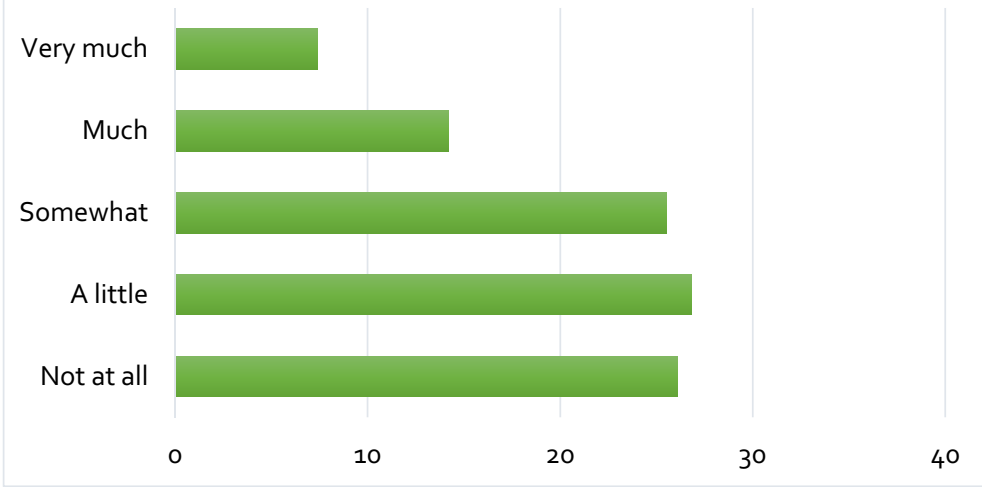

Fig. 1 The distribution of perceived discrimination among the Romanian migrants

poor relations with the natives, and have limited interactions with other migrants are associated with a higher likelihood to perceive individual discrimination. Among these hypothesized effects, the relations with natives and the job below capabilities correlate the strongest $(-0.31$, respectively 0.30$)$. The empirical evidence goes against the hypothesis formulate for the attachment to the own group (H3).

People who feel higher emotional attachment to their home country (and implicitly to the ethnic group to which they belong) are more likely to feel discriminated against. One possible explanation for this positive correlation is that individuals with high levels of attachment to their ethnic group can perceive as individual discrimination any remarks addressed to their group; it could be difficult for these respondents to differentiate between group and individual discrimination. Another possible explanation is the existence of situations in which the group of ethnic Romanians is stigmatized (e.g., as it happened in Italy in 2007 after one Romanian murdered an Italian woman). The strong attachment to a stigmatized group could determine respondents to identify discrimination even in cases in which this was not actually present.

Table 1 Correlations between the perception of discrimination and other variables

\begin{tabular}{llr}
\hline & Correlation coefficient & $N$ \\
\hline Job below capabilities & $0.30^{* *}$ & 1839 \\
Planned duration of stay & $-0.18^{* *}$ & 1839 \\
Attachment to own group & $0.18^{*}$ & 1798 \\
Relations with natives & $-0.31^{* *}$ & 1839 \\
Interactions with other migrants & $-0.12^{* *}$ & 1800 \\
Length of residency & $0.08^{* *}$ & 1839 \\
Language difficulties & $0.15^{* *}$ & 1839 \\
Education & $-0.07^{* *}$ & 1839 \\
Age & 0.02 & 1785 \\
Gender & -0.04 & 1828 \\
\hline
\end{tabular}

The correlation coefficients are non-parametric (Spearman)

$* * p<0.01 ; * p<0.05$ 
The correlations between three controls and the dependent variable are statistically significant at the 0.01 level. Among them, language difficulties correlate the highest with perceived discrimination (0.15): respondents who had difficulties with the language of the host country indicated more discrimination compared with the other Romanian migrants. People who live longer in the country of residence perceive more individual discrimination compared with those who lived less $(0.08)$, probably due to the fact that they were exposed more to situations in which discrimination could occur. Less educated respondents perceive more individual discrimination $(-0.07)$ and this could be explained, on the one hand, through a more limited understanding of what stands for discrimination (i.e., they could misinterpret some actions as being discriminatory when they are not) and, on the other hand, to the working environment. Migrants with lower education take up poorly paid jobs where the likelihood of facing discrimination is higher. Age and gender do not appear to be correlated with the perception of discrimination.

\section{Multivariate Regression Analysis}

The results of the regression analysis are included in Table 2 and bring additional information to what revealed by the correlations. The interpretation of results is relative to the group of migrants who feel no individual discrimination, i.e., the reference category. Model 1 includes all five predictors from the hypothesized relationships and confirms the results of the correlations. The strongest effect is for H4: the Romanian migrants who have poor relations with the natives are almost three times more likely to feel discriminated against compared with the other respondents; when the odds ratios are lower than 1, the interpretation presents their logarithm. These results provide empirical evidence to previous explanations from the literature according to which good relationships between migrants and those in the host society contribute to a positive social climate in which discrimination is unlikely to occur or be perceived (Shorey et al. 2002; Motti-Stefanidi and Asendorpf 2012). Conversely, poor relations usually reflect limited integration in the host society and can lead to tensions. For the Romanian migrants who answered the survey, the feeling of perceived discrimination is significantly higher among those who do not go along well with the natives. This confirms earlier findings according to which the Romanian migrants in Spain see the existence of an unequal relationship between them and the locals (Marcu 2015).

The second strongest effect is observed for H1. Respondents who perform a job below their level of education and qualification are 2.76 times more likely to feel individual discrimination in comparison with those respondents whose jobs match their capabilities. These results confirm earlier findings that point in the direction of higher vulnerability to perceived individual discrimination among migrants performing jobs below their capabilities. The migrants with high qualifications are subject to long working hours and precarious work conditions (Ciupijus 2011) that they often did not anticipate. When reaching a new country of destination, some migrants start from the bottom and accept jobs below their capabilities, which makes it easier for them to understand when the locals look down on them (Marcu 2015). Under these circumstances, there is frustration at the workplace and they can perceive employers' behavior as adversarial and discriminatory more than other migrants. This category of migrants 
Table 2 Ordinal logistic regression for the perception of discrimination

\begin{tabular}{lll}
\hline & Model 1 & Model 2 \\
\hline Job below capabilities & $2.76^{* *}(0.25)$ & $2.78^{* *}(0.26)$ \\
Planned duration of stay & $0.88^{* *}(0.02)$ & $0.91^{* *}(0.03)$ \\
Attachment to own group & $1.27^{* *}(0.05)$ & $1.26^{* *}(0.05)$ \\
Relations with natives & $0.52^{* *}(0.03)$ & $0.51^{* *}(0.03)$ \\
Interactions with other migrants & $0.93^{*}(0.04)$ & $0.92^{*}(0.04)$ \\
Length of residency & & $1.43^{* *}(0.07)$ \\
Language difficulties & & $1.29^{* *}(0.12)$ \\
Education & & $0.95(0.03)$ \\
Age & & $1.02^{* *}(0.01)$ \\
Gender & & $0.95(0.09)$ \\
$N$ & 1766 & 1712 \\
Pseudo $R^{2}$ & 0.07 & 0.08 \\
Log likelihood & -2498.74 & -2391.44 \\
\hline
\end{tabular}

Reported coefficients are odds ratios (standard errors in brackets)

$* * p<0.01 ; * p<0.05$

is likely to have lower levels of expectation fulfilment towards everyday life in the host society. This can lead to frustration and greater sensitivity towards the environment in which they live and thus to higher perceptions about discrimination.

The effects for $\mathrm{H} 2$ and $\mathrm{H} 3$ have similar strength. The migrants who plan their stay for a longer term and those who feel strongly about their ethnic group are roughly 1.3 times more likely to feel discrimination compared with the rest of migrants. All these effects are statistically significant at the 0.01 level. The fifth hypothesized relationship is the weakest and shows that the respondents who interact less with other migrants are 1.1 times more likely to feel discriminated against; this effect is significant at the 0.05 level.

Model 2, which includes the controls, has a higher value of the pseudo $R^{2}$ which means that this model better fits the outcome data than the previous model. Since this is a pseudo $R^{2}$, it does not say much about the explanatory power of the model and cannot be interpreted independently, it is useful to assess the two models predicting the same outcome on the same dataset. The direction, size, and statistical significance of the main effects remains largely unchanged. Among the controls, the strongest predictor is the length of residency with those Romanian migrants who spent more time in the host country being 1.43 times more likely to perceive discrimination. This is the third largest effect in model 2, stronger than some of the main effects (e.g., $\mathrm{H} 2$ or H3).

Language difficulties are also quite strong with respondent reporting this issue being 1.29 times more likely to perceive discrimination. The bivariate analysis showed that language difficulties correlate higher than length of residency with the perceptions of discrimination. Such an observation can add relevant information to the general picture about Romanian migrants and the choice of their destinations. Earlier research indicates that language plays a role in how they choose the country of residence (Anghel 2013). If high perception of discrimination is a consequence of language problems, the latter is 
relevant for social integration in the broader sense. In the multivariate regression analysis, the length of residency gains prominence. Age is the third control that is statistically significant, but the size of effect is very small showing that younger respondents (since age is coded as the year of birth) are 1.02 times more likely to feel discriminated than older Romanian migrants. Education and gender lack statistical significance and this is different from the bivariate relationships, i.e., education was statistically significant.

These empirical results lead to three major conclusions. First, the development of good relations with the native population reduces the likelihood of perceived discrimination (Fig. 2). If migrants begin the process of integration in the host society through connections with the natives, they have more opportunities to understand the local culture (including the way of thinking) and are thus more likely to avoid misunderstandings and even feel welcome. All these can contribute to positive feelings between individuals belonging to different ethnic groups, which limit the opportunities for discriminatory behavior. This observation is strengthened by the empirical evidence about the positive effect of interactions with other groups of migrants on perceived discrimination. When respondents to this survey engaged with other members of their community and avoided isolation, the likelihood to perceive discrimination was lower.

Second, the perception of discrimination is unlikely to be lower in the future among many labor migrants since three of its drivers are stable features of the migration process: the types of jobs, difficulties with the language of the host society, and planned stay. The first two variables are often positively correlated and the same happens for our sample of Romanian migrants: positive correlation of 0.17 , statistically significant at the 0.01 level. A great deal of labor migrants occupies jobs below their capacity when arriving first to a country. This experience can make them more sensitive to discriminatory practices and attitudes. The empirical evidence in this article shows that the jobs below capability are an important trigger for the perceptions of discrimination, fairly equal in size with the positive relations with natives but in the opposite direction (Fig. 2).

Some Romanian migrants have difficulties with the language of the host country upon arrival, which triggers uncertainty and makes them more vulnerable to bad treatment from other people. Many Romanian labor migrants are oriented towards a temporary stay (Ambrosini et al. 2015) and the evidence in this article indicates that short planned stays favor the perception of discrimination. The short-term migrants are


Fig. 2 The effect of relations with natives and job on perceptions of discrimination 
usually oriented towards financial gains and the cultural interactions-which decrease discrimination - are on a secondary place. This can be also coupled with the existence of multiple migration in which some of the Romanian migrants change their country of residence based on several reasons out of which one is a cost-benefit analysis (Ciobanu 2015). For these migrants, the change of destination involves a series of new challenges and experiences that are sometimes associated with discrimination.

Third, a longer stay in the country of residence is not sufficient to lower the perceptions of discrimination. On the contrary, the results of this analysis illustrate that length of residency increases the likelihood of such perceptions probably due to the large number of situations to which migrants are exposed. Another possible explanation is that migrants are likely to become more disillusioned over time, especially when they experience deskilling. ${ }^{2}$ Consequently, the perceived discrimination is limited when migrants use the time spent in the host society to integrate and to avoid isolation. Equally important, our study revealed that the sociocultural characteristics such as education, age, and gender do not have a relevant impact on perceived discrimination. This means that the perception of discrimination often occurs independently from the structure of the group of migrants.

\section{Conclusions}

This article sought to identify and analyze what determines the perceptions of discrimination among Romanian migrants. So far, little systematic research has tried to understand why migrants perceive discrimination. It has tested for the effect of several individual-level factors and found that human relationships (with natives and other migrants) and work-related issues are the key drivers for such perceptions. The positive relations with natives and length of residency, on the one hand, and jobs below capabilities and language difficulties especially at work, on the other hand, have opposite effects on the perceptions of discrimination. All these indicate that the variation in perception of discrimination is mainly due to what migrants actively do once they reach the host society and very rarely due to demographic characteristics.

The implications of this study reach beyond its sample of respondents. The major theoretical advancement is the identification of a set of variables that can be used for the study of perceived discrimination. The latter is thus not only a cause of various problems occurred in the process of migration (e.g., impact on mental health) but can also be a consequence. The explanatory power of the model proposed here can contribute to the general theoretical discussion about the importance of the environment, groups, and individuals in migrants' adaptation to the new realities of the host country. The study makes a theoretical contribution to the attributional perspective by nuancing and refining its effects on the perception of discrimination. Our findings confirm the importance of relations with the natives in the formation of perceptions. However, they also indicate the limited explanatory potential of esteem for the group to which the migrants belong and the number of interactions with other groups of migrants. In this sense, we illustrate that the attributes that matter are related to the host society.

\footnotetext{
${ }^{2}$ I would like to thank one of the anonymous reviewers of this journal for suggesting this explanation.
} 
Another implication of our study is the conceptual and empirical separation between the qualitative and quantitative interactions with natives and members of other migrant groups. Our results show that these components have a different effect on perceptions of discrimination and it is useful to treat them separately. On the same empirical note, the relevance of the five hypothesized determinants illustrates that perceptions of discrimination have several causes and is not the consequence of a single determinant. In this sense, a separate investigation of the work factors, society related, or sociocultural perspective provide only a limited account.

These are at least two possible ways in which the findings of the current study could serve as point of departure for future analyses. This study is limited to a group of first-generation migrants from Romania. Further research could empirically explore these relationships for different groups of migrants. These groups can be different in terms of their experience with migration, but also have different countries of origin and of residence. The overview of Romanian migration indicates the existence of several waves with their own characteristics. A future study could look into how diverse groups of migrants, from different waves, perceive discrimination. A comparative analysis along these lines could produce more robust results about the convergence or divergence of explanations. Although it reveals important patterns and trends, this study could not explore deeper the causal relationships. In this sense, a qualitative analysis could be a fruitful direction for future research. Such an avenue can take the form of interviews or focus groups with the aim to unveil how their perception about discrimination is formed. This approach would also allow the identification of differences in terms of perceived discrimination between countries of residence, which are not detected with the current method of investigation.

\section{Appendix}

Table 3 Summary statistics of the variables included in the analysis

\begin{tabular}{|c|c|c|c|c|c|}
\hline & Mean & Std dev & Min & Max & $N$ \\
\hline Perception of discrimination & 2.50 & 1.22 & 1 & 5 & 1839 \\
\hline Job below capabilities & 0.39 & 0.49 & 0 & 1 & 1839 \\
\hline Planned duration of stay & 2.16 & 1.61 & 0 & 4 & 1839 \\
\hline Attachment to own group & 3.93 & 1.12 & 1 & 5 & 1798 \\
\hline Relations with natives & 4.12 & 0.80 & 1 & 5 & 1839 \\
\hline Interactions with other migrants & 3.20 & 1.16 & 1 & 5 & 1800 \\
\hline Length of residency & 4.22 & 1.08 & 1 & 5 & 1839 \\
\hline Language difficulties & 0.44 & 0.50 & 0 & 1 & 1839 \\
\hline Education & 5.63 & 1.32 & 1 & 7 & 1839 \\
\hline Age (year of birth) & 1979 & 11 & 1937 & 1999 & 1785 \\
\hline Gender & 1.44 & 0.50 & 1 & 2 & 1828 \\
\hline
\end{tabular}


Open Access This article is licensed under a Creative Commons Attribution 4.0 International License, which permits use, sharing, adaptation, distribution and reproduction in any medium or format, as long as you give appropriate credit to the original author(s) and the source, provide a link to the Creative Commons licence, and indicate if changes were made. The images or other third party material in this article are included in the article's Creative Commons licence, unless indicated otherwise in a credit line to the material. If material is not included in the article's Creative Commons licence and your intended use is not permitted by statutory regulation or exceeds the permitted use, you will need to obtain permission directly from the copyright holder. To view a copy of this licence, visit http://creativecommons.org/licenses/by/4.0/.

\section{References}

Agudelo-Suárez, A., Gil-González, D., Ronda-Pérez, E., Porthé, V., Paramio-Pérez, G., García, A. M., \& Garí, A. (2009). Discrimination, work and health in immigrant populations in Spain. Social Science \& Medicine, 68, 1866-1874.

Aichberger, M. C., Bromand, Z., Rapp, M. A., Yesil, R., Montesinos, A. H., Temur-Erman, S., Heinz, A., \& Schouler-Ocak, M. (2015). Perceived ethnic discrimination, acculturation, and psychological distress in women of Turkish origin in Germany. Social Psychiatry and Psychiatric Epidemiology, 50(11), 16911700 .

Ambrosini, J. W., Mayr, K., Peri, G., \& Radu, D. (2015). The selection of migrants and returnees in Romania: evidence and long-run implications. Economics of Transition and Institutional Change, 23(4), 753-793.

Anderson, B., Clark, N., \& Parutis, V. (2008). New EU Members? Migrant workers' challenges and opportunities to UK trades unions: a Polish and Lithuanian case study. Oxford: Compas.

Anghel, R. (2013). Romanians in Western Europe: migration, status dilemmas, and transnational connections. Lanham: Lexington Books.

Brody, G. H., Chen, Y. F., Murry, V. M. B., Ge, X., Simons, R. L., Gibbons, F. X., Gerrard, M., \& Cutrona, C. E. (2006). Perceived discrimination and the adjustment of African American youths: a five-year longitudinal analysis with contextual moderation effects. Child Development, 77(5), 1170-1189.

Ciobanu, R. O. (2015). Multiple migration flows of Romanians. Mobilities, 10(3), 466-485.

Ciupijus, Z. (2011). 'Mobile central eastern Europeans in Britain: successful European Union citizens and disadvantaged labour migrants?', Work. Employment and Society, 25(3), 540-550.

Constant, A., \& Massey, D. S. (2002). Return migration by German guestworkers: neoclassical versus new economic theories. International Migration, 40(4), 5-38.

Dospinescu, A., \& Russo, G. (2018) Romania: systematic country diagnostic. World Bank Group. Available at: http://documents.worldbank.org/curated/en/210481530907970911/pdf/128064-SCD-PUBLICP160439-RomaniaSCDBackgroundNoteMigration.pdf.

Dustmann, C., \& Weiss, Y. (2007). Return migration: theory and empirical evidence from the UK. British Journal of Industrial Relations, 45(2), 236-256.

Dustmann, C., Bentolila, S., \& Faini, R. (1996). 'Return migration: the European experience', Economic Policy. Oxford University Press, 11(22), 213-250.

Dustmann, C., Fadlon, I., \& Weiss, Y. (2011). Return migration, human capital accumulation and the brain drain. Journal of Development Economics, 95(1), 58-67.

Elrick, T., \& Ciobanu, O. (2009). Migration networks and policy impacts: insights from Romanian-Spanish migrations. Global Networks, 9(1), 100-116.

Emmel, N. (2013). Sampling and choosing cases in qualitative research: a realist approach. London: Sage Publications.

Finch, B. K., Kolody, B., \& Vega, W. A. (2000). Perceived discrimination and depression among Mexicanorigin adults in California. Journal of Health and Social Behavior, 41(3), 295-313.

Floyd, M. F., \& Gramann, J. H. (1995). Perceptions of discrimination in a recreation context. Journal of Leisure Research, 27(2), 192-199.

Fox, J. E., Moroşanu, L., \& Szilassy, E. (2015). Denying discrimination: status, "race”, and the whitening of Britain's new Europeans. Journal of Ethnic and Migration Studies, 41(5), 729-748.

Gee, G. C., Ryan, A., Laflamme, D. J., \& Holt, J. (2006). Self-reported discrimination and mental health status among African descendants, Mexican Americans, and other Latinos in the New Hampshire REACH 2010 Initiative: the added dimension of immigration. American journal of public health, 96(10), 1821-1828. 
Gherghina, S. (2016). Making voices count: the political participation of Romanian immigrants in Western Europe. East European Politics, 32(2), 258-276.

Gherghina, S. and Plopeanu, A. (2020) 'Who wishes to return? Ties to home country among the Romanian migrants', Nationalities Papers, (online first).

Goto, S. G., Gee, G. C., \& Takeuchi, D. T. (2002). Strangers still? The experience of discrimination among Chinese Americans. Journal of Community Psychology, 30(2), 211-224.

Hansen, K. L. (2015). Ethnic discrimination and health: the relationship between experienced ethnic discrimination and multiple health domains in Norway's rural Sami population. International Journal of Circumpolar Health, 74(1), 1-12.

Hatch, S. L., et al. (2016). Discrimination and common mental disorder among migrant and ethnic groups: findings from a South East London Community sample. Social Psychiatry and Psychiatric Epidemiology, 51(5), 689-701.

Inman, M., \& Baron, R. S. (1996). Influence of prototypes on perceptions of prejudice. Journal of personality and social psychology, 70(4), 727-739.

International Organization for Migration. (2020). World Migration Report 2020. Geneva: United Nations.

Keys, H. M., Kaiser, B. N., Foster, J. W., Burgos Minaya, R. Y., \& Kohrt, B. A. (2015). Perceived discrimination, humiliation, and mental health: a mixed-methods study among Haitian migrants in the Dominican Republic. Ethnicity \& Health, 20(3), 219-240.

Kobrynowicz, D., \& Branscombe, N. R. (1997). Who considers themselves victims of discrimination?: Individual difference predictors of perceived gender discrimination in women and men. Psychology of Women Quarterly, 21(3), 347-363.

Krieger, N., Waterman, P. D., Hartman, C., Bates, L. M., Stoddard, A. M., Quinn, M. M., Sorensen, G., \& Barbeau, E. M. (2006). Social hazards on the job: workplace abuse, sexual harassment, and racial discrimination - a study of black, Latino, and white low-income women and men workers in the United States. International Journal of Health Services, 36(1), 51-85.

MacKenzie, R., \& Forde, C. (2009). 'The rhetoric of the "good worker" versus the realities of employers' use and the experiences of migrant workers', Work. Employment and Society, 23(1), 142-159.

Marcu, S. (2015). 'From the marginal immigrant to the mobile citizen: reconstruction of identity of Romanian migrants in Spain', Population. Space and Place, 21(6), 506-517.

McDowell, L., Batnitzky, A., \& Dyer, S. (2008). Internationalization and the spaces of temporary labour: the global assembly of a local workforce. British Journal of Industrial Relations, 46(4), 750-770.

McKay, S., Craw, M., \& Chopra, D. (2006). Migrant workers in England and Wales. An assessment of migrant worker health and safety risks. London: London Metropolitan University.

Moreno, M. A., Goniu, N., Moreno, P. S., \& Diekema, D. (2013). Ethics of social media research: common concerns and practical considerations. Cyberpsychology, Behavior, and Social Networking, 16(9), 708713.

Motti-Stefanidi, F., \& Asendorpf, J. B. (2012). Perceived discrimination of immigrant adolescents in Greece: how does group discrimination translate into personal discrimination? European Psychologist, 17(2), 93104.

Patton, M. Q. (2005). Qualitative research. In B. S. Everitt \& D. Howell (Eds.), Encyclopedia of Statistics in Behavioral Science (Vol. 3, pp. 1633-1636). Chichester: Wiley.

Pedersen, M. J., \& Nielsen, C. V. (2016). Improving survey response rates in online panels. Social Science Computer Review, 34(2), 229-243.

Phinney, J. S., Ferguson, D. L., \& Tate, J. D. (1997). Intergroup attitudes among ethnic minority adolescents: a causal model. Child Development, 68(5), 955-969.

Phinney, J. S., Madden, T., \& Santos, L. J. (1998). Psychological variables as predictors of perceived ethnic discrimination among minority and immigrant adolescents. Journal of Applied Social Psychology, 28(11), 937-953.

Ruggiero, K. M., \& Taylor, D. M. (1995). Coping with discrimination: how disadvantaged group members perceive the discrimination that confronts them. Journal of Personality and Social Psychology, 68(5), $826-838$.

Ruggiero, K. M., \& Taylor, D. M. (1997). Why minority group members perceive or do not perceive the discrimination that confronts them: the role of self-esteem and perceived control. Journal of Personality and Social Psychology, 72(2), 373-389.

Sandu, D. (2006). Temporary stay abroad. Romanians' economic migration: 1990-2006. Bucharest: The Open Society Foundation.

Sandu, D., et al. (2004). A country report on Romanian migration abroad: stocks and flows after, 1989. 
Sangalang, C. C., Becerra, D., Mitchell, F. M., Lechuga-Peña, S., Lopez, K., \& Kim, I. (2019). Trauma, postmigration stress, and mental health: a comparative analysis of refugees and immigrants in the United States. Journal of Immigrant and Minority Health, 21(5), 909-919.

Schreier, M. (2018). Sampling and generalization. In U. Flick (Ed.), The SAGE Handbook of Qualitative Data Collection (pp. 84-98). London: Sage Publications.

Shorey, H. S., Cowan, G., \& Sullivan, M. P. (2002). Predicting perceptions of discrimination among Hispanics and Anglos. Hispanic Journal of Behavioral Sciences, 24(1), 3-22.

Stănculescu, S., \& Stoiciu, M. (2012). Impactul crizei economice asupra migratiei fortei de munca din Romania (The Impact of Financial Crisis on the Labor Migration in Romania). Bucharest: Paideia.

Stark, O. (1996). On the microeconomics of return migration. In V. N. Balasubramanyam \& D. Greenaway (Eds.), Trade and development. Essays in Honour of Jagdish Bhagwati (pp. 32-41). Basingstoke: Palgrave Macmillan.

Strohmeier, D., Kärnä, A., \& Salmivalli, C. (2011). Intrapersonal and interpersonal risk factors for peer victimization in immigrant youth in Finland. Developmental Psychology, 47(1), 248-258.

Suciu, O.-V. (2010) 'Migration and demographic trends in Romania: a brief historical outlook', Paper presented at the CRCE 2010 Colloquium.

Sue, V. M., \& Ritter, L. A. (2012). Conducting online surveys. London: Sage Publications.

Szczepura, A. et al. (2004) Review of occupational health and safety of Britain's ethnic minorities. Research Report 221. Available at: www.hse.gov.uk/research/rrpdf/rr221.pdf.

Tajfel, H. (1982). Social psychology of intergroup relations. Annual Review of Psychology, 33(1), 1-39.

Trandafoiu, R. (2013). Diaspora online. identity politics and Romanian migrants. New York: Berghahn Books.

Turner, J. C. (1981). Towards a cognitive redefinition of the social group. Cahiers de Psychologie Cognitive / Current Psychology of Cognition, 1(2), 93-118.

Vega, W. A., Khoury, E. L., Zimmerman, R. S., Gil, A. G., \& Warheit, G. J. (1995). Cultural conflicts and problem behaviors of Latino adolescents in home and school environments. Journal of Community Psychology, 23(2), 167-179.

Vintila, C. D., \& Soare, S. (2018) Report on political participation of mobile EU citizens: Romania. Florence.

Wong, C. A., Eccles, J. S., \& Sameroff, A. (2003). The influence of ethnic discrimination and ethnic identification on African American adolescents' School and Socioemotional Adjustment. Journal of Personality, 71(6), 1197-1232.

Yang, D. (2006). Why do migrants return to poor countries? Evidence from Philippine Migrants' responses to exchange rate shocks. Review of Economics and Statistics, 88(4), 715-735.

Zschirnt, E., \& Ruedin, D. (2016). Ethnic discrimination in hiring decisions: a meta-analysis of correspondence tests 1990-2015. Journal of Ethnic and Migration Studies, 42(7), 1115-1134.

Publisher's Note Springer Nature remains neutral with regard to jurisdictional claims in published maps and institutional affiliations. 